Research Article

\title{
Carvedilol versus beta-1 blockers as anti-hypertensive drugs in type-2 diabetes mellitus and pre-diabetic patients with features of metabolic syndrome: a meta-analysis
}

\author{
Sharanabasayyaswamy B. Hiremath ${ }^{1 *}$, Srinivas Devendrappa Lokikere ${ }^{2}$
}

\begin{abstract}
${ }^{1}$ Department of Pharmacology, SDM Medical College, Dharwad, Karnataka, India ${ }^{2}$ Department of Pharmacology, JJM Medical College, Davangere, Karnataka, India
\end{abstract}

Received: 23 April 2016

Accepted: 03 June 2016

\section{*Correspondence to:}

Dr. Sharanabasayyaswamy B.

Hiremath,

Email: dr.sharan83@yahoo.com

Copyright: () the author(s), publisher and licensee Medip Academy. This is an openaccess article distributed under the terms of the Creative Commons Attribution NonCommercial License, which permits unrestricted noncommercial use, distribution, and reproduction in any medium, provided the original work is properly cited.

\begin{abstract}
Background: It is unclear and contradictory on to whether carvedilol is preferable over beta-1 blockers as add-on drug in hypertensive pre-diabetic and diabetic patients with metabolic syndrome. The objective of this study was to compare the effects of carvedilol versus beta-1 blockers on hemodynamic parameters, indicators of insulin resistance and plasma lipid levels in hypertensive diabetic and pre-diabetic patients with features of metabolic syndrome.

Methods: Electronic database search in Pubmed, Cochrane library and EMBASE was conducted. Randomized or cross-over studies comparing effects of carvedilol against beta-1 blockers were included under analysis. Statistical analysis by inverse variance method and both random and fixed effect models was conducted by using RevMan 5.3.

Results: Six studies were eligible and included in the analysis. There was minor but significant decrease in SBP (mean difference, $\mathrm{MD}=-1.38 \mathrm{~mm} \mathrm{Hg}, 95 \% \mathrm{CI}=$ $-2.09,-0.66)$ and $\mathrm{HbA} 1 \mathrm{C} \%(\mathrm{MD}=-0.21 \%, 95 \% \mathrm{CI}-0.41$ to -0.02$)$ by carvedilol in patients with type-2 DM.

Conclusions: There is moderate quality of evidence to suggest that carvedilol has mild but significant SBP and $\mathrm{HbA} 1 \mathrm{C} \%$ lowering effect compared to beta-1 blockers in hypertensive patients with type-2 DM.
\end{abstract}

Keywords: Carvedilol, Beta-1 blockers, Type-2 DM, Hypertension, Metabolic syndrome

\section{INTRODUCTION}

Metabolic syndrome or insulin resistance syndrome is diagnosed based on the presence of three or more of the following five criteria: central obesity, raised triglycerides $(\geq 150 \mathrm{mg} / \mathrm{dl})$, reduced HDL cholesterol $(<40$ $\mathrm{mg} / \mathrm{dl}$ ), raised blood pressure (systolic $\mathrm{BP} \geq 130 \mathrm{~mm} \mathrm{Hg}$ or diastolic $\mathrm{BP} \geq 85 \mathrm{~mm} \mathrm{Hg}$ ) and raised fasting plasma glucose (FPG $\geq 100 \mathrm{mg} / \mathrm{dl}$ ) or previously diagnosed type-2 DM. ${ }^{1}$ Visceral or central obesity is the common and major etiological factor responsible for development of metabolic syndrome. Development of insulin resistance (fasting serum insulin level of $>25 \mathrm{mIU} / \mathrm{l}$ ) is the major initial patho-physiological event responsible for mediating subsequent events and complications of metabolic syndrome. ${ }^{2,3}$ Hyper-insulinemia induced due to decreased tissue sensitivity to insulin is responsible for sodium retention, sympathetic nervous system stimulation, vascular smooth muscle hypertrophy and oxidative stress. ${ }^{2,3}$ Hence insulin resistance represents the mechanism or basis for development of hypertension in type-2 DM and vice-versa. Major complication of metabolic syndrome in pre-diabetics is risk of onset of type-2 DM and in existing diabetics the higher incidences 
of cardiovascular related events like myocardial infarction, stroke etc. ${ }^{2,3}$

Theoretically, anti-hypertensive drugs preferred in treating diabetic and especially pre-diabetic patient with metabolic syndrome are those with neutral or favourable metabolic effects. The favourable metabolic effect of an anti-hypertensive drug may become quite significant in preventing risk of onset of type-2 DM in a pre-diabetic patient. However this favourable metabolic effect of an anti-hypertensive drug may not be of major significance in treating a hypertensive diabetic patients provided the drug reduces blood pressure to target level. ${ }^{4}$ Infact, this evidences from 'ALLHAT' study do not favour any class of anti-hypertensive drugs including angiotensin converting enzyme Inhibitors (ACE-Is) or angiotensin-II receptor blockers (ARBs) as preferable or first choice anti-hypertensive drugs in metabolic syndrome even though they have proved beneficial effects on insulin resistance. ${ }^{5}$ Nevertheless evidences still justify selection of ACE-Is or ARBs as first choice anti-hypertensive drugs especially in elderly, in obese, in pre-diabetics and also support their superiority over other classes of antihypertensive drugs with regard to lower incidence of endstage kidney disease and cardiovascular risks in type-2 DM patients. ${ }^{6-10}$ So the preferred drugs to be used at least in hypertensive pre-diabetic patients are perhaps ACE-Is or ARBs. Need for another anti-hypertensive drug as an add-on or second line drug to ACE-Is or ARBs with favourable effect on metabolic parameters is relevant especially in pre-diabetics for two reasons. First, to achieve decrease in blood pressure to target level without risk of converting them to diabetics and second, to have the added benefits of ACE-Is/ARBs but without added adverse effects like hyperkalaemia. Second line drugs with either favourable or neutral effect on metabolic effects are third generation beta-blocker like carvedilol, alpha-1 selective blockers, dihydropyridine (DHPs) calcium channel blockers and imidazolin-1 agonists. ${ }^{11-13}$ Major drawback behind selecting alpha-1 blockers as add-on drugs is their association with higher incidences of heart failure as monotherapy. ${ }^{4}$ Hence the best second line anti-hypertensive drug to be added in pre-diabetic patients with metabolic syndrome needs selection from either DHPs or carvedilol or imidazolin-1 agonists.

It is unclear whether carvedilol is preferable over to beta1 blockers in hypertensive pre-diabetic patients with metabolic syndrome from the point of preventing them from becoming diabetics. There are unclear and contradictory evidences on to whether carvedilol is preferable over to beta-1 blockers in hypertensive patients with type-2 DM in presence of other antihypertensive or anti-diabetic or lipid lowering drugs. Hence our study aims to clarify these questions and to quantify the effects of carvedilol on hemodynamic parameters and major metabolic parameters compared to beta-1 blockers in presence of other anti-hypertensive or anti-diabetic or lipid lowering drugs in hypertensive patients with type-2 DM and pre-diabetics with features of metabolic syndrome.

\section{METHODS}

\section{Literature Search methodology}

Two authors independently conducted electronic database search in Pubmed, Cochrane library and EMBASE for the randomized trials or cross-over trials with head-tohead comparison of effects of carvedilol versus beta-1 blockers in patients of hypertension with metabolic syndrome of both pre-diabetic and diabetic type. Independent searches were conducted by two authors using MeSH search terms "carvedilol" and "hypertension" and "metabolic syndrome" and "carvedilol" and "hypertension" and "diabetes mellitus" separately. Limits applied for the search in Pubmed were "randomized controlled studies", and "humans" while the limits applied for search in EMBASE were "randomized controlled trial" "conference paper" "article" "article in press" "embase" and "humans". No limits were applied in Cochrane library search. Manual search of the references of the relevant articles and reviews was also conducted to identify missed studies. Search was limited to studies published up to $30^{\text {th }}$ July 2015 and was not restricted to any language.

\section{Inclusion criteria}

- Studies of either cross-over or randomized design,

- Head-to-head comparison of carvedilol versus beta-1 blockers,

- In patients of either sex aged $>18$ years, with primary hypertension and features of metabolic syndrome.

\section{Exclusion criteria}

- Studies with short duration of treatment (<1month)

- Studies including patients with other co-morbid diseases (heart failure, arrhythmia, myocardial infarction, etc.)

- Studies published in language other than English

- Studies with incomplete data required for statistical analysis

- Studies published as abstracts.

\section{Data extraction and data synthesis}

Two authors were involved in independent extraction of all required data in a pre-designed standard data extraction form. Differences between the authors on to the data extracted were resolved after achieving consensus between the authors and then the final data sheet was prepared. Data extracted included baseline clinical and demographic data, data on individual study characteristics like year of publication, study design, duration, interventions used, sample size, outcome measures used, etc. Changes observed in systolic and diastolic blood pressure, heart rate, plasma lipid level. 
Fasting plasma glucose (FPG), fasting serum insulin (FSI), HOMA-IR (homeostatic model assessment-insulin resistance) index and $\mathrm{HbA} 1 \mathrm{C} \%$ values at the study endpoint were extracted. Parameters on safety were not extracted as this was not the objective of our study. Most of the studies published baseline values versus study endpoint values and not the "mean change" values (calculated as difference between baseline values and study endpoint values) to compare the effect of drugs. Because of this limitation we used study endpoint values in analysing the 'effect size' measures between carvedilol and beta-1 selective blockers considering that there is insignificant differences in the baseline values of all the outcome measures in two comparator groups in all the studies. Studies publishing data as "mean change" values were used in separate estimation. Data required analysing the effect on FSI level, FPG level, HOMA-IR index, $\mathrm{HbA} 1 \mathrm{C} \%$, plasma lipid levels were not available from all the studies. Data on SBP and DBP were available from all the studies.

After extracting the data, values published as standard error of mean (SEM) were converted into standard deviation (SD) by using formula: $\mathrm{SD}=\mathrm{SEM} \times \sqrt{\mathrm{N}}(\mathrm{N}=$ sample size). Some of the studies published fasting glucose values and plasma lipid concentration values using the unit mmol/l and were converted to $\mathrm{mg} / \mathrm{dl}$ by considering $1 \mathrm{mmol} / \mathrm{l}$ glucose $=18.016 \mathrm{mg} / \mathrm{dl}$ and 1 $\mathrm{mmol} / \mathrm{l}$ cholesterol $=38.66 \mathrm{mg} / \mathrm{dl}$. Likewise, serum insulin levels published as $\mu \mathrm{IU} / \mathrm{ml}$ were converted to $\mathrm{pmol} / \mathrm{l}$ considering $1 \mu \mathrm{IU} / \mathrm{ml}=6.945 \mathrm{pmol} / \mathrm{l}$. Sufficient data required for statistical analysis were not available from GEMINI study, the largest and longest study among all the included studies and hence we used data from four sub-studies published based on the data from GEMINI study. ${ }^{14-17}$ Still, the sufficient data required for statistical estimation of effect size on lipid parameters were not available from one of the GEMINI sub-study. ${ }^{17}$ Data published in some of these sub-studies did not reported standard deviation but instead reported $95 \%$ confidence intervals. These values were used to calculate standard deviation values using the standard formula $(S D=\sqrt{ } \mathrm{N} x$ (upper limit-lower limit)/3.92). Data on the results of outcome measures were available at the end of both 12 weeks and 24 weeks in study by Martsevich et al. ${ }^{18} \mathrm{We}$ used 12 weeks data only in the analysis of short term (2-3 months) treatment effects and 24 weeks study in longterm (5-6 months) treatment effects as well as in 'major analysis' (including data of all eligible studies irrespective of type of co-morbidity and duration of the study).

\section{Outcome measures}

The primary outcome measures were changes in $\mathrm{HbA} 1 \mathrm{C} \%$ while and the secondary outcome measures were changes in hemodynamic parameters (SBP, DBP, heart rate) indicators of insulin resistance (FPG or FSI or HOMA-IR index) and plasma lipid levels at the end of study period. Subgroup analyses of these outcome measures according to type of co-morbidity (pre-diabetics or type-2 DM), according to duration of treatment (short term or long term), and use of other antihypertensive drugs (yes or no) were also conducted.

\section{Statistical analysis}

Changes in the outcome measures between two groups were assessed by calculating the "mean difference' (MD) values. Inverse-variance statistical method and both fixed and random effect models were used in analysis. Sensitivity analysis of the results was conducted by comparing results of random effect model with fixed effects model. Heterogeneity between the studies was analysed by using Cochrane $\mathrm{Q}$ test for heterogeneity and $\mathrm{I} 2$ test. A chi square test with $\mathrm{P}$ value $<0.10$ and $\mathrm{I} 2$ test value of $>50 \%$ was considered as indicator of significant heterogeneity. Statistical analysis was conducted by using RevMan software version 5.3.

Funnel plot method was used for assessment of publication bias. An asymmetric inverted funnel shape was considered as an indicator of publication bias in the studies. Un-blinded quality assessment of eligible studies as described by Nancy et al., was independently done by two authors. ${ }^{19}$ In this method, 39 questions analysing quality of various aspects like study design, study subjects, control groups, eligibility criteria used, treatment protocol, study methodology, outcome measures used, apart from funding sources and type of journal publishing the study Each question will be allotted one mark and the total marks obtained by individual study will be translated into percentages. Final score for the individual studies was allotted only after resolving the differences if any and arriving at consensus between the authors.

\section{RESULTS}

\section{Literature search results}

Figure 1 shows the results of literature search and the attrition diagram with number of studies excluded and reasons for their exclusion. Excluded studies did not involve studies published in language other than English. Six studies were eligible and included in the analysis of which four were on type-2 DM patients and other two were on pre-diabetics. ${ }^{14,18,20-23}$ Study by Martsevich et al was identified by manual search of the references of relevant articles. This study was published in both English and Russian language. A small $(\mathrm{N}=19)$ and short term $(8$ weeks) study by kveiborg et al comparing carvedilol versus metaprolol on patients with type-2 DM was excluded due to lack of clarity regarding presence of metabolic syndrome in the included patients. ${ }^{24}$ A separate analysis was conducted including this study to analyse if any major differences in results occur due to its inclusion of this study. Of the six studies included four studies compared carvedilol with metaprolol and in remaining 
two studies atenolol and bisoprolol were used as beta-1 blockers.

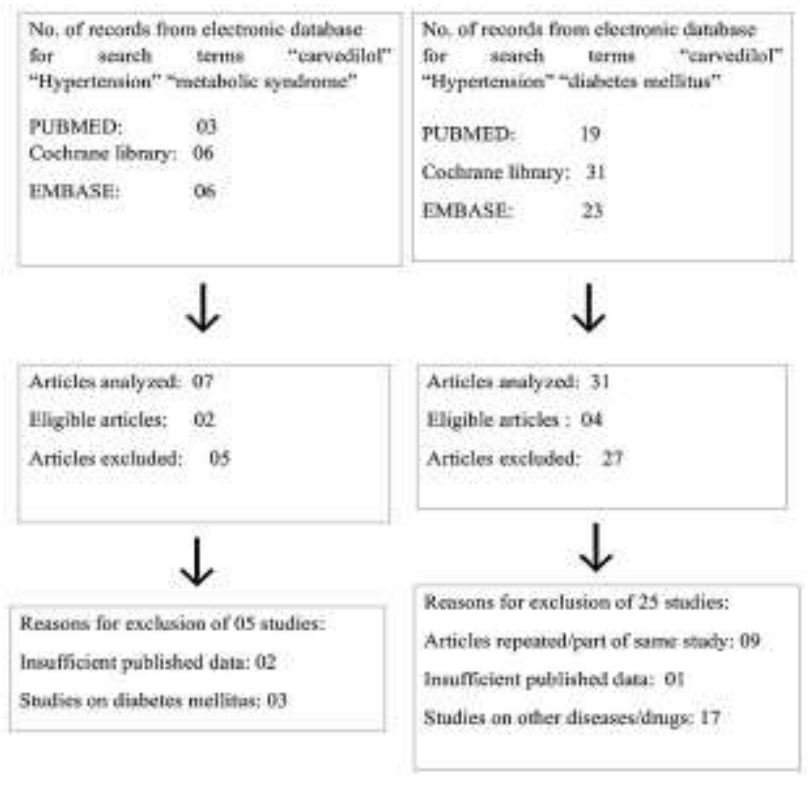

Figure 1: Attrition diagram showing database search results.

\section{Characters of included patients and studies}

Tables 1, 2 and 3 show the baseline demographic, clinical features and characteristics of the individual studies and patients included in the analysis. Statistically insignificant differences in the baseline demographic and clinical features between the two comparator groups were reported in all the studies. Except for in the GEMINI study by Bakris et al none of the studies mentioned about the ethnicity of the patients included in the study. However, considering the country of origin of other studies, majority of patients included could perhaps be considered as ethnic white population. Most of the patients included in all the studies belonged to satge- 1 and stage- 2 hypertension. There was no major variation in the dose of carvedilol used $(25-50 \mathrm{mg} / \mathrm{d})$ in all studies except for in study by Ehmer et al where double dose (50-100 $\mathrm{mg} / \mathrm{d}$ ) was used perhaps due to higher baseline blood pressure level in this study population compared to other studies. However the studies varied significantly with regards to use of concomitant medications. In studies by Bakris et al, Morshwitch et al and Bank et al ACE-Is or ARBs used before randomization were continued and subsequently either a DHP and or a diuretic was added in order to achieve target level blood pressure. ${ }^{14,18,20}$

Table 1: Baseline demographic and clinical feature of patients included in eligible studies.

\begin{tabular}{|c|c|c|c|c|c|c|}
\hline \multirow[t]{2}{*}{ Factors } & \multicolumn{2}{|c|}{ Bakris et al } & \multicolumn{2}{|c|}{ Bank et al } & \multicolumn{2}{|c|}{ Ehmer et al } \\
\hline & C-group & M-group & C-group & M-group & C-group & M-group \\
\hline $\mathrm{N}$ & 498 & 737 & 16 & 18 & 25 & 24 \\
\hline Age (years) & $60.7 \pm 9.4$ & $61.1 \pm 9.7$ & $60.9 \pm 8.5$ & $61.9 \pm 9.9$ & $59(23-77)^{€}$ & $57(25-80)^{€}$ \\
\hline BMI & $33.5 \pm 5.8$ & $33.7 \pm 6.2$ & $33.7 \pm 5.1$ & $34.4 \pm 6.4$ & NA & NA \\
\hline $\mathrm{M} / \mathrm{F}$ & $300 / 198$ & $338 / 354$ & $12 / 4$ & $12 / 6$ & $14 / 11$ & $15 / 9$ \\
\hline Heart rate & $73.7 \pm 0.5^{t}(\mathrm{~N}=454)$ & $74.5 \pm 0.4^{\mathrm{t}}(\mathrm{N}=636)$ & NA & NA & $77.4 \pm 9.4$ & $74.4 \pm 7.6$ \\
\hline SBP (mmHg) & $149.4 \pm 0.6^{\mathrm{t}}(\mathrm{N}=454)$ & $149.2 \pm 0.5^{t}(\mathrm{~N}=636)$ & $146 \pm 10$ & $151 \pm 13$ & $173.1 \pm 16.6$ & $166 \pm 11.7$ \\
\hline DBP (mmHg) & $87 \pm 0.4^{\mathrm{t}}(\mathrm{N}=454)$ & $86.3 \pm 0.4^{\mathrm{t}}(\mathrm{N}=636)$ & $86 \pm 13$ & $85 \pm 8$ & $102.5 \pm 3.5$ & $100.6 \pm 3.4$ \\
\hline FPI (pmol/l) & $150 \pm \mathrm{NA}^{\mathrm{t}}(\mathrm{N}=387)$ & $147.2 \pm \mathrm{NA}^{\mathrm{t}}(\mathrm{N}=561)$ & $125 \pm 62.5$ & $83.34 \pm 55.5$ & NA & NA \\
\hline FPG (mg/dl) & $147 \pm \mathrm{NA}^{\mathrm{t}}(\mathrm{N}=387)$ & $147.4 \pm \mathrm{NA}^{\mathrm{t}}(\mathrm{N}=561)$ & $133 \pm 38$ & $145 \pm 43$ & $144.2 \pm 33.5$ & $157.9 \pm 39.6$ \\
\hline $\mathrm{HbA} 1 \mathrm{C} \%$ & $7.21 \pm 0.55$ & $7.19 \pm 0.54$ & $7.3 \pm 1.1$ & $7.0 \pm 0.9$ & NA & NA \\
\hline HOMA & $6.0 \pm \mathrm{NA}^{\mathrm{t}}(\mathrm{N}=371)$ & $5.8 \pm \mathrm{NA}^{\mathrm{t}}(\mathrm{N}=540)$ & $5.9 \pm 3.7$ & $4.8 \pm 4.4$ & NA & NA \\
\hline $\mathrm{TC}(\mathrm{mg} / \mathrm{dl})$ & $185.6 \pm \mathrm{NA}(\mathrm{N}=433)$ & $185.6 \pm \mathrm{NA}(\mathrm{N}=625)$ & $176 \pm 38$ & $169 \pm 28$ & $236.2 \pm 35.3$ & $253.3 \pm 58.7$ \\
\hline TGs (mg/dl) & $159.4 \pm \mathrm{NA}(\mathrm{N}=433)$ & $168.3 \pm \mathrm{NA}(\mathrm{N}=625)$ & $155 \pm 57$ & $151 \pm 35$ & $202.2 \pm 83.9$ & $168 \pm 59.8$ \\
\hline HDL-C (mg/dl) & $46.4 \pm \mathrm{NA}(\mathrm{N}=432)$ & $46.4 \pm \mathrm{NA}(\mathrm{N}=625)$ & $46 \pm 9$ & $44 \pm 9$ & $48.8 \pm 11.3$ & $47.4 \pm 12$ \\
\hline LDL-C (mg/dl) & $186.6 \pm \mathrm{NA}(\mathrm{N}=411)$ & $100.5 \pm \mathrm{NA}(\mathrm{N}=572)$ & $105 \pm 33$ & $95 \pm 23$ & $151.1 \pm 32.1$ & $176.4 \pm 50.6$ \\
\hline
\end{tabular}

$*=$ Significant difference, All values are in mean $\pm \mathrm{SD}, \mathrm{t}=$ least square mean $\pm \mathrm{SE}, €=$ mean(range), NA= Not Available, $\mathrm{HOMA}=$ Homeostasis model assessment, M/F: Male Female ratio, TC $=$ Total Cholesterol, TGs $=$ Triglycerides, FPI =Fasting Plasma Insulin, FPG $=$ Fasting Plasma Glucose, $\mathrm{N}=$ Total number of patients, $\mathrm{C}=$ Carvedilol, $\mathrm{M}=$ Metaprolol

In studies by Bakris et al and Bank et al lipid lowering and anti-diabetic drugs were also used. Type of antidiabetic drugs used was unclear in study by Bank et al. ${ }^{20}$ In the remaining studies no ACE-Is or ARBs or any other anti-hypertensive drugs were used and the target blood pressure level was achieved by doubling the dose of the test drugs only. ${ }^{21-23}$ Of the four studies conducted on patients of type-2 DM, the type of anti-DM drug used in studies by Giugliano et al and Ehmer et al was sulfonylureas (SUs) and no drug which increases insulin sensitivity was used. ${ }^{21,22}$ These therapeutic variations and 
variation in the patients characteristic of the included study could be a major reason for inter-trial heterogeneity. However, we tried to nullify the effects of these factors by conducting various sub-group analyses. Quality score achieved by all six studies was more than $75 \%$.

Table 2: Baseline demographic and clinical feature of patients included in eligible studies.

\begin{tabular}{|c|c|c|c|c|c|c|}
\hline \multirow[t]{2}{*}{ Factors } & \multicolumn{2}{|l|}{ Giugliano et al } & \multirow{2}{*}{$\begin{array}{c}\text { Jacob et al } \\
\text { C-group }\end{array}$} & \multicolumn{2}{|c|}{ Martsevich et al } & \multirow[b]{2}{*}{ B-group } \\
\hline & C-group & A-group & & M-group & C-group & \\
\hline $\mathrm{N}$ & 23 & 22 & 34 & 36 & 53 & 52 \\
\hline Age (years) & $57.5 \pm 6.5$ & $58.2 \pm 6.9$ & $49 \pm 1.7$ & $51 \pm 1.6$ & $46.6 \pm 13.3$ & $45.6 \pm 12.8$ \\
\hline BMI & $27.9 \pm 3.7$ & $28.3 \pm 4.1$ & $27.2 \pm 0.7$ & $28.2 \pm 0.6$ & $31.5 \pm 3.7$ & $31.0 \pm 3.1$ \\
\hline $\mathrm{M} / \mathrm{F}$ & $13 / 10$ & $12 / 10$ & $19 / 15$ & $26 / 10$ & NA & NA \\
\hline Heart rate & $74 \pm 8.5$ & $72 \pm 9.1$ & $75.5 \pm 2.0$ & $72.4 \pm 2.0$ & $77.6 \pm 7.2$ & $76.8 \pm 8.1$ \\
\hline $\mathrm{SBP}(\mathrm{mm} \mathrm{Hg})$ & $160.9 \pm 13$ & $163.1 \pm 14$ & $153.9 \pm 3.2$ & $151.5 \pm 3.6$ & $154.8 \pm 11.4$ & $152.5 \pm 10.8$ \\
\hline $\mathrm{DBP}(\mathrm{mm} \mathrm{Hg})$ & $99.1 \pm 4.5$ & $98.1 \pm 3.9$ & $96.83 \pm 1.6$ & $92.1 \pm 1.6$ & $94.6 \pm 8.0$ & $94.7 \pm 6.0$ \\
\hline FPI (pmol/l) & $77 \pm 46$ & $69 \pm 37$ & NA & NA & $\begin{array}{l}76.4 \pm 74.3 \\
(\mathrm{~N}=48)\end{array}$ & $69.4 \pm 71.5(\mathrm{~N}=50)$ \\
\hline FPG (mg/dl) & $163.9 \pm 23.4$ & $160.3 \pm 21.6$ & NA & NA & $\begin{array}{l}100.1 \pm 18 \\
(\mathrm{~N}=48)\end{array}$ & $100.3 \pm 21.2(\mathrm{~N}=50)$ \\
\hline $\mathrm{HbA} 1 \mathrm{C} \%$ & $7.6 \pm 0.8$ & $7.5 \pm 09$ & NA & NA & NA & NA \\
\hline HOMA & $0.048 \pm 0.02$ (ISI) & $0.055 \pm 0.02$ (ISI) & $7.81 \pm 0.8$ & $8.66 \pm 0.7$ & $\begin{array}{l}2.91 \pm 3.4 \\
(\mathrm{~N}=48)\end{array}$ & $2.58 \pm 3.2(\mathrm{~N}=50)$ \\
\hline $\mathrm{TC}(\mathrm{mg} / \mathrm{dl})$ & $216.5 \pm 27$ & $224.2 \pm 31$ & $232.0 \pm 8.1$ & $241.4 \pm 7.9$ & $\begin{array}{l}209.5 \pm 45.2 \\
(\mathrm{~N}=48)\end{array}$ & $212.6 \pm 37.8(\mathrm{~N}=50)$ \\
\hline TGs (mg/dl) & $71.1 \pm 30.9$ & $65.7 \pm 34.8$ & $157.5 \pm 24.6$ & $155 \pm 12.1$ & $\begin{array}{l}73.8 \pm 38.6 \\
(\mathrm{~N}=48)\end{array}$ & $70.3 \pm 38.2(\mathrm{~N}=50)$ \\
\hline HDL-C (mg/dl) & $41.7 \pm 7.7$ & $41.36 \pm 7.7$ & $49.5 \pm 3.2$ & $52.2 \pm 2.6$ & $\begin{array}{l}44.8 \pm 13.9 \\
(\mathrm{~N}=48)\end{array}$ & $45.6 \pm 12(\mathrm{~N}=50)$ \\
\hline LDL-C (mg/dl) & NA & NA & $148.3 \pm 9.9$ & $155.5 \pm 9.2$ & $\begin{array}{l}127.53 \pm 36.7 \\
(\mathrm{~N}=48)\end{array}$ & $133 \pm 34(\mathrm{~N}=50)$ \\
\hline
\end{tabular}

* Significant difference, All Values are Mean \pm SD, HOMA $=$ Homeostasis model assessment N/A = Not Available, ISI $=$ Insulin Sensitivity Index (calculated as $\mathrm{mg} / \mathrm{kg}$ x min $/ \mathrm{mIU} / \mathrm{l}$ x 100) $\mathrm{M} / \mathrm{F}=$ Male Female ratio, $\mathrm{TC}=$ Total Cholesterol, TGs = Triglycerides, FPI $=$ Fasting Plasma Insulin, FPG = Fasting Plasma Glucose, $\mathrm{N}=$ Total number of patients, $\mathrm{C}=$ Carvedilol, $\mathrm{M}=\mathrm{Metaprolol}, \mathrm{A}=$ Atenelol, B = Bisoprolol.

\section{Outcome measures}

Considering the possibility of significant inter-trial heterogeneity, we present the results of random effects model as representatives of true effect size measures. Results if significant in fixed effect model will be presented as representatives of true effect provided there is an indication of lack of significant heterogeneity. Table. 4 and Figure 2 show the effects size measures of various outcome measures in 'major analysis' and two sub-group analyses after including studies conducted on pre-diabetic patients and type-2 DM patients.

\section{Effect on hemodynamic parameters}

Only significant change observed in hemodynamic parameter was decrease in $1.4 \mathrm{~mm} \mathrm{Hg}$ of SBP by carvedilol in sub-group analysis of studies including only type-2 DM patients. Interestingly, the difference remained significant even after exclusion of ethnic black population of GEMINI study from the analysis (MD $=-1.38$ (95\% CI $=-2.1,-0.67)$. There was no significant effect of both comparator groups on heart rate.

\section{Effect on indicators of insulin resistance}

Only significant change observed among all the indicators of insulin resistance was decrease in $\mathrm{HbA} 1 \mathrm{C} \%$ by $0.22 \%$ in subgroup analysis including only type-2 DM patients. Unlike the effect on SBP, this effect was absent after exclusion of ethnic black population of GEMINI study from the analysis $(\mathrm{MD}=-0.22(95 \% \mathrm{CI}=-0.44$, $0.01)$.

Effect on lipid parameters: Significant changes observed in favour of carvedilol were decrease in total cholesterol by $12 \mathrm{mg} / \mathrm{dl}$ and LDL cholesterol by $12 \mathrm{mg} / \mathrm{dl}$ in subgroup analysis including only short term treatment studies. Same two parameters were found to be significantly decreased by carvedilol in subgroup analysis of studies including pre-diabetic patients only (Table 3). 
Table 3: Characters and quality scores of individual studies.

\begin{tabular}{|c|c|c|c|c|c|}
\hline Study & $\begin{array}{l}\text { Study design } \\
\text { and country }\end{array}$ & $\begin{array}{l}\text { Patients } \\
\text { features }\end{array}$ & $\begin{array}{l}\text { Intervention and } \\
\text { duration }\end{array}$ & Other medications & $\begin{array}{l}\text { Quality } \\
\text { score }\end{array}$ \\
\hline $\begin{array}{l}\text { Bakris } \\
\text { et al }\end{array}$ & $\begin{array}{l}\text { Randomized } \\
\text { Double blind } \\
\text { Parallel group } \\
\text { Multicentre USA }\end{array}$ & $\begin{array}{l}\text { Type-2DM } \\
\text { HTN-1 and } 2\end{array}$ & $\begin{array}{l}\text { C:6.25-25 mg BD } \\
\text { M:50-200 mg BD } 5 \\
\text { months }\end{array}$ & $\begin{array}{l}\text { ACEIs/ARBs } \\
\text { Thiazides, DHPs } \\
\text { Hypolipidemics } \\
\text { Anti-DM -SU's -TZD }\end{array}$ & $88.2 \%$ \\
\hline $\begin{array}{l}\text { Bank } \\
\text { et al }\end{array}$ & $\begin{array}{l}\text { Randomized } \\
\text { Double blind } \\
\text { Parallel group } \\
\text { single centre, USA }\end{array}$ & $\begin{array}{l}\text { Type-2DM } \\
\text { HTN-1 and } 2\end{array}$ & $\begin{array}{l}\text { C: } 6.25-25 \mathrm{mg} \\
\text { BD } \\
\text { M:50-200mg } \\
\text { BD } 5 \text { months }\end{array}$ & $\begin{array}{l}\text { ACEIs/ARBs } \\
\text { Thiazides, DHPs } \\
\text { Hypolipidemics } \\
\alpha \text {-blockers, Anti-DM }\end{array}$ & $84.8 \%$ \\
\hline $\begin{array}{l}\text { Ehmer } \\
\text { et al }\end{array}$ & $\begin{array}{l}\text { Randomized } \\
\text { Un-blinded } \\
\text { Parallel group } \\
\text { Single centre } \\
\text { Germany } 2 \text { months }\end{array}$ & $\begin{array}{l}\text { Type-2DM } \\
\text { HTN-1 and } 2\end{array}$ & $\begin{array}{l}\text { C:25-50mg } \\
\text { BD (SUs) } \\
\text { M:50-100mg } \\
\text { BD }\end{array}$ & Anti-DM & $75.7 \%$ \\
\hline $\begin{array}{l}\text { Giugliano } \\
\text { et al }\end{array}$ & $\begin{array}{l}\text { Randomized } \\
\text { Double blind } \\
\text { Parallel group } \\
\text { single centre Italy }\end{array}$ & $\begin{array}{l}\text { Type-2DM } \\
\text { HTN-1 and } 2\end{array}$ & $\begin{array}{l}\text { C:25-50 mg OD } \\
\text { A:50-100 mg OD } \\
6 \text { months }\end{array}$ & Anti-DM (SUs) & $78.7 \%$ \\
\hline $\begin{array}{l}\text { Jacob } \\
\text { et al }\end{array}$ & $\begin{array}{l}\text { Randomized } \\
\text { Double blind } \\
\text { Parallel group } \\
\text { Multi centre } \\
\text { Germany }\end{array}$ & $\begin{array}{l}\text { Pre-diabetic } \\
\text { HTN-1 and } 2\end{array}$ & $\begin{array}{l}\text { C: } 25-50 \mathrm{mg} \text { OD } \\
\text { M:50-100 mg OD } \\
2 \text { months }\end{array}$ & None & $81.8 \%$ \\
\hline $\begin{array}{l}\text { Morshwitch } \\
\text { et al }\end{array}$ & $\begin{array}{l}\text { Randomized } \\
\text { Open label } \\
\text { Parallel group } \\
\text { Single centre Russia }\end{array}$ & $\begin{array}{l}\text { Pre-diabetic } \\
\text { HTN-1 and } 2\end{array}$ & $\begin{array}{l}\text { C: } 12.5-25 \mathrm{mg} \mathrm{BD} \\
\mathrm{B}: 5-10 \mathrm{mg} \text { OD } \\
6 \text { months }\end{array}$ & $\begin{array}{l}\text { ACEIs/ARBs } \\
\text { Thiazides, DHPs } \\
\text { Anti-platelets } \\
\text { Anti-DM -Statins }\end{array}$ & $75.7 \%$ \\
\hline
\end{tabular}

SU:Sulfonyl ureas, TZD:Thiazolidinediones, DHP:Dihydropyridine; $\mathrm{C}=$ Carvedilol, $\mathrm{M}=$ Metaprolol, $\mathrm{B}=\mathrm{Bisoprolol}, \mathrm{A}=\mathrm{Atenelol}$.

Table 4: Effect size values of primary and secondary outcome measures.

\begin{tabular}{|c|c|c|c|c|c|c|}
\hline \multirow[t]{2}{*}{ Parameters } & \multirow{2}{*}{$\begin{array}{l}\text { All studies }{ }^{\#} \\
\text { Effect size }\end{array}$} & \multicolumn{3}{|c|}{ Type-2 DM studies } & \multicolumn{2}{|l|}{ Pre-diabetics studies } \\
\hline & & $\mathbf{N}(\mathbf{n})$ & Effect size & $\mathbf{N}(\mathbf{n})$ & Effect size & $\mathbf{N}(\mathbf{n})$ \\
\hline $\mathrm{TC}(\mathrm{mg} / \mathrm{dl})$ & $-5.97(-15.66,3.72)$ & $251(4)$ & $1.55(-19.89,22.99)$ & $83(2)$ & $-13.06 *(-24.83,-1.29)$ & $168(2)$ \\
\hline HDL (mg/ dl) & $1.92(-1.23,5.08)$ & $251(4)$ & $3.54(-1.73,8.81)$ & $83(2)$ & $1.63(-2.55,5.81)$ & $168(2)$ \\
\hline $\mathrm{LDL}(\mathrm{mg} / \mathrm{dl})$ & $-8.03(-18.00,1.93)$ & $251(4)$ & $-2.18(-17.47,13.12)$ & $83(2)$ & $-13.28 *(-25.23,-1.33)$ & $168(2)$ \\
\hline TGs (mg /dl) & $0.84(-10.8,12.48)$ & $251(4)$ & $-31.95(-75.6,11.7)$ & $83(2)$ & $-10.65(-25.25,3.95)$ & $168(2)$ \\
\hline $\mathrm{SBP}(\mathrm{mm} \mathrm{Hg})$ & $0.92(-2.08,3.92)$ & $1341(6)$ & $-1.38 *(-2.09,-0.66)$ & $1173(4)$ & $2.59(-1.46,6.65)$ & $168(2)$ \\
\hline $\begin{array}{l}\mathrm{SBP}^{\$} \\
\text { (Mean change) }\end{array}$ & $-0.68(-2.19,0.83)$ & $1135(2)$ & $-0.68(-2.19,0.83)$ & $1135(2)$ & NA & NA \\
\hline $\mathrm{DBP}(\mathrm{mm} \mathrm{Hg})$ & $0.88(-0.45,2.22)$ & $1341(6)$ & $0.12(-0.29,0.52)$ & $1173(4)$ & $2.55(-1.9,7.01)$ & $168(2)$ \\
\hline $\begin{array}{l}\mathrm{DBP}^{\$} \\
\text { (mean change) }\end{array}$ & $0.06(-0.96,1.07)$ & $1135(2)$ & $0.06(-0.96,1.07)$ & $1135(2)$ & NA & NA \\
\hline HR & $1.93(-2.16,6.02)$ & $217(3)$ & NA & NA & $3.89(-1.79,9.56)$ & $168(2)$ \\
\hline FPG (mg/dl) & $2.64(-5.26,10.53)$ & $251(4)$ & NA & NA & $2.34(-1.87,6.56)$ & $168(2)$ \\
\hline FPI (pmol/l/1) & $-9.53(-34.36,15.29)$ & $132(2)$ & NA & NA & NA & NA \\
\hline $\mathrm{HbA} 1 \mathrm{C} \%$ & NA & NA & NA & NA & NA & NA \\
\hline $\begin{array}{l}\mathrm{HbA} 1 \mathrm{C} \% \\
\text { 'mean change' }\end{array}$ & $-0.22 *(-0.41,-0.03)$ & $1156(2)$ & $-0.22 *(-0.14,-0.03)$ & $1156(2)$ & NA & NA \\
\hline HOMA** & $-0.6(-1.59,0.4)$ & $132(2)$ & NA & NA & NA & NA \\
\hline
\end{tabular}

$*$ * statistically significant. All values are Mean Difference (95\% Confidence Interval). \# = All studies includes Bank et al., Ehmer et al., Jacob et al., Morshwitch et al., Giugliano et al. and Bakris et al. \$ = 'mean change'values were available from Giugliano et al. and Bakris et al. $\mathrm{N}=$ Total number of patients included; $\mathrm{n}=$ total number of studies included.N/A = Not Available, FPG $=$ Fasting Plasma Glucose, FPI = Fasting Plasma Insulin, TC $=$ Total cholesterol, TGs $=$ Triglycerides . 


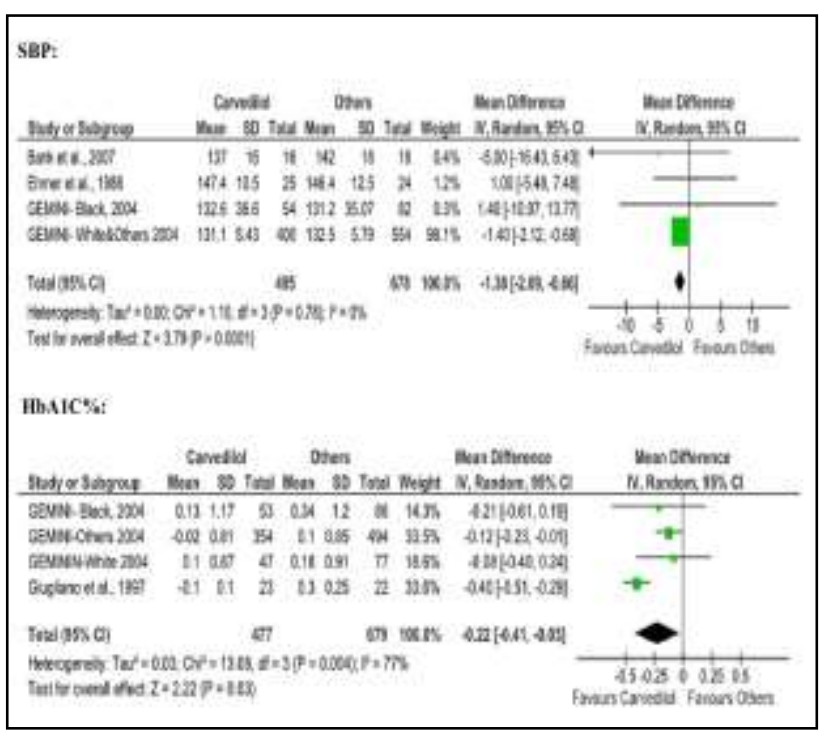

\section{Figure 2: Forest plot of effects of carvedilol on SBP and $\mathrm{HbA1C} \%$.}

There was evidence of significant inter-trial heterogeneity and publication bias in all of these significant results except for the results of total cholesterol and LDL cholesterol. After inclusion of study by kveiborg et al the significant change observed was decrease in $\mathrm{HbA} 1 \mathrm{C} \%$ by carvedilol. With regard to hemodynamic parameters, there was significant decrease in SBP level by carvedilol only in subgroup analysis of studies on patients with type-2 DM. An distinct observation which was evident due to inclusion of this study was significant decrease in HDL cholesterol by carvedilol. In addition, there was significant decrease in FPG in subgroup analysis of studies including type-2 DM patients.

\section{DISCUSSION}

Results of our study suggest that carvedilol has minor but significant effect on SBP and HbA1C\% compared to beta1 blockers especially metaprolol in type-2 DM patients. Though carvedilol was not superior, we did not observed the inferiority of it with regards to BP lowering effects compared to other beta- 1 blockers as was observed in an indirect evidence from a meta-analysis. ${ }^{24}$ From the observation of individual included studies on SBP and DBP, what was uniformly evident in all these studies was that the major effect of beta-1 blockers was on lowering DBP. Carvedilol too had similar effect on DBP in addition to slightly higher level of decrease in SBP. Hence these observations support the evidences that betablockers may have limited effect on pulse pressure owing to their major effect on reducing DBP. ${ }^{25}$ Marginally higher effect of carvedilol on SBP observed in our study can be explained on the basis of its additional vasodilator action. This minor quantity of effect on SBP may not be translated into greater effect on pulse pressure and hence the effect of carvedilol may be similar to other beta- blockers. ${ }^{24}$ Significance of reducing pulse pressure was evident in 'ALLHAT' study wherein even the ACE-I with favorable metabolic effect was inferior to diuretic with regard to reduction of stroke and heart failure perhaps due to insignificant decrease in pulse pressure achieved by ACE-I compared to diuretic. Beta blockers too have drawback of lack of protective effect against stroke, heart failure and found to be inferior to other three major classes of anti-hypertensive drugs in reducing overall mortality. $^{26,27}$ Whether these results can also be extrapolated to carvedilol is uncertain since these observations were drawn on non-selective beta-blocker propranolol and atenolol. If the reason for failure of betablockers is strongly attributed to their insignificant effect on pulse pressure, then even carvedilol may also prove to be indifferent from other beta-1 selective and nonselective beta-blockers. The effect of carvedilol in prediabetic patients with metabolic syndrome is perhaps restricted to lowering of LDL cholesterol and total cholesterol levels. Absence of significant effect of carvedilol on any of the indicators of insulin resistance and hemodynamic parameters indicates non-inferiority of other beta-1 blockers especially bisoprolol and metaprolol in this population. The minor differences observed between carvedilol and metaprolol with regard to their effects on metabolic parameters perhaps are of no major importance in the light of results of 'ALLHAT' study and 'ACCORD' study, both highlighting the importance of achieving target blood pressure level. ${ }^{4,28}$ One of the aspects where carvedilol may prove to be better over beta1 blockers is in its favourable effect of on micro albuminuria, perhaps due to its additional anti-oxidant activity. ${ }^{29}$ Other aspects where superiority of carvedilol over beta-1 blockers found was with respect to reduction in the incidence of new onset type-2 DM in patients of heart failure. ${ }^{30}$ Hence in patients with significant micro albuminuria and in patients of heart failure at risk of type2 DM carvedilol can be preferred over beta- 1 blockers.

In a nutshell, from looking at all the present available evidences, treatment of hypertensive and or diabetic patients and role of carvedilol can be summarized as follows. A patient of uncontrolled type-2 DM has very high chances of becoming hypertensive due to detrimental effects of hyperinsulinemia. A hypertensive patient without type-2 DM obviously gets benefits of lowering blood pressure to normal level but a type-2 DM patient even without hypertension gets benefits of lowering of blood pressure to below the normal level highlighting the importance of lowering blood pressure. ${ }^{4,28}$ Once the diabetic patient becomes hypertensive, intensive control of blood glucose level and selecting an antihypertensive with favourable metabolic profile may not be of much significance. However a hypertensive pre-diabetic patient with features of metabolic syndrome would certainly need an anti-hypertensive with favourable or neutral effects on metabolic parameters in order to avoid hyperinsulinemia and thus becoming overt diabetic. Since the presence of 
type-2 DM acts as a major factor contributing to higher mortality and if the hypertensive patient succumbs to heart failure, the major aim of treating with antihypertensive drugs in pre-diabetic patients should be to avoid heart failure and onset of type-2 DM. Drugs like thiazide diuretics stand superior to ACE-Is or ARBs and DHPs in terms of reduction in incidence of heart failure in patients with primary hypertension. Whether carvedilol as a representative of beta-blockers is superior to any of these three major classes of anti-hypertensive drugs in this regard needs to be further analysed.

\section{CONCLUSION}

To conclude, there is moderate quality of evidence to suggest that carvedilol has mild but significant SBP and $\mathrm{HbA} 1 \mathrm{C} \%$ lowering effect compared to beta-1 blockers in hypertensive patients with type-2 DM. Considering the available low quality evidences from subgroup analysis in pre-diabetic patients, carvedilol may not be superior to metaprolol or bisoprolol in preventing onset of type-2 DM in these patients. The additional anti-oxidant effect of carvedilol may be the major determinant responsible for its observed clinical benefits rather than its hemodynamic effects or favourable metabolic effect. Major drawback of our study is lack of availability of complete data and uniformity in the available data from all studies. Availability and use of study end point values instead of 'mean change' values from few studies may not represent true effects and is unjustifiable in estimation of true effect size. Apart from this drawback, including studies of small sample size and one study of very large sample size could be a major source of heterogeneity. Considering the drawbacks of our study extrapolating the results of our study to general population needs cautious interpretation.

Funding: No funding sources Conflict of interest: None declared

Ethical approval: Not required

\section{REFERENCES}

1. Parikh RM, Mohan V. Changing definitions of metabolic syndrome. Indian $\mathrm{J}$ Endocr Metab. 2012;16:7-12.

2. Roberts CK, Hevener AL, Barnard RJ. Metabolic syndrome and insulin resistance: underlying causes and modification by exercise training. Compr Physiol. 2013;3:1-58.

3. Israili ZH, Lyoussi B, Rafael HH, Velasco M. Metabolic syndrome: treatment of hypertensive patients. American Journal of Therapeutics. 2007; 14:386-402.

4. Furberg CD, Wright JT, Davis B. Major outcomes in high-risk hypertensive patients randomized to angiotensin-converting enzyme inhibitor or calcium channel blocker versus diuretic: the antihypertensive and lipid-lowering treatment to prevent heart attack trial (ALLHAT). JAMA. 2002;288:2981-97.
5. Yang Y, Wei RB, Wang ZC, Wang N, Gao YW, Li $\mathrm{MX}$, et al. A meta-analysis of the effects of angiotensin converting enzyme inhibitors and angiotensin II receptor blockerson insulin sensitivity in hypertensive patients without diabetes. Diabetes Res Clin Pract. 2015;107(3):415-23.

6. Dahlöf B, Devereux RB, Kjeldsen SE, Julius S, Beevers G, De Faire U, et al. Cardiovascular morbidity and mortality in the losartan intervention for endpoint reduction in hypertension study (LIFE): A randomised trial against atenolol. Lancet. 2002;359:995-1003.

7. Wing LM, Reid CM, Ryan P, Beilin LJ, Brown MA, Jennings GL, et al. A comparison of outcomes with angiotensin-converting enzyme inhibitors and diuretics for hypertension in the elderly. N Engl J Med. 2003;348:583-92.

8. Cooper-dehoff RM, Handberg EM, Mancia G, Zhou Q, Champion A, Legler UF, et al. INVEST revisited: a review of findings from the international verapamil SR-trandolapril study (INVEST). Expert Rev Cardiovasc Ther. 2009;7:1329-40.

9. Palmer SC, Mavridis D, Navarese E, Craig JC, Tonelli M, Salanti G, et al. Comparative efficacy and safety of blood pressure-lowering agents in adults with diabetes and kidney disease: a network metaanalysis. Lancet. 2015;385:2047-56.

10. Agodoa L, Baigent C, Black H, Boissel JP, Brenner B. Effects of different blood pressure-lowering regimens on major cardiovascular events in individuals with and without diabetes mellitus. Arch Intern Med. 2005;165:1410-9.

11. Torres YC, Katholi RE. Novel treatment approaches in hypertensive type 2 diabetic patients. World J Diabetes. 2014;5:536-45.

12. Schachter M. Metabolic effects of moxonidine and other centrally acting antihypertensives. Diabetes Obes Metab. 1999;1:317-22.

13. Hansson L. Therapy of hypertension and metabolic syndrome: today's standard and tomorrow's perspectives. Blood Press suppl. 1998;3:20-2.

14. Bakris GL, Fonseca V, Katholi RE, McGill JB, Messerli FH, Phillips RA, et al. Metabolic effects of carvedilol versus metoprolol in patients with type 2 diabetes mellitus and hypertension: a randomized controlled trial. JAMA. 2004;292:2227-36.

15. Wright JT, Bakris GL, Bell DS, Fonseca V, Katholi $\mathrm{RE}, \mathrm{McGill} \mathrm{JB}$, et al. Lowering blood pressure with beta-blockers in combination with other reninangiotensin system blockers in patients with hypertension and type 2 diabetes: results from the GEMINI Trial. J Clin Hypertens (Greenwich). 2007;9:842-9.

16. Phillips RA, Fonseca V, Katholi RE, McGill JB, Messerli FH, Bell DS, et al. Demographic analyses of the effects of carvedilol versus metoprolol on glycemic control and insulin sensitivity in patients with type 2 diabetes and hypertension in the glycemic effects in diabetes mellitus: carvedilol-metoprolol 
comparison in hypertensives (GEMINI) study. J Cardiometab Syndr. 2008;3:211-7.

17. Bell DS, Bakris GL, McGill JB. Comparison of carvedilol and metoprolol on serum lipid concentration in diabetic hypertensive patients. Diabetes Obes Metab. 2009;11:234-8.

18. Martsevich SY, Tolpygina SN. Comparison of the influence of long-term treatment based on carvedilol or bisoprolol on metabolic parameters in hypertensive patients with overweight or obesity. Results of the randomized open-label parallel-groups steppped trial CABRIOLET (part I). Rational Pharmacother Card. 2012;8:488-99.

19. Nancy GB, Robert AP. Meta-analysis: neither quick nor easy. BMC medical research methodology. 2002;2:1-9.

20. Bank AJ, Kelly AS, Thelen AM, Kaiser DR, Gonzalez-Campoy MJ. Effects of carvedilol versus metoprolol on endothelial function and oxidative stress in patients with type 2 diabetes mellitus. AJH. 2007;20:777-83.

21. Giugliano D, Acampora R, Marfella R, De Rosa N, Ziccardi P, Ragone R, et al. Metabolic and cardiovascular effects of carvedilol and atenolol in non-insulin-dependent diabetes mellitus and hypertension a randomized, controlled trial. Ann Intern Med. 1997;126:955-9.

22. Ehmer B, van der Does R, Rudorf J. Influence of carvedilol on blood glucose and glycohaemoglobin al in non-insulin-dependent diabetics. Drugs. 1988;36:136-40.

23. Jacob S, Rett K, Wicklmayr M, Agrawal B, Auguatin HJ, Dietze GJ. Differential effect of chronic treatment with two beta-blocking agents on insulin sensitivity: the carvedilol-metaprolol study. Journal of hypertension. 1996;14:489-94.
24. Wong GWK, Laugerotte A, Wright JM. Blood pressure lowering efficacy of dual alpha and beta blockers for primary hypertension. Cochrane Database of Systematic Reviews. 2015;8:CD007449.

25. Chen JMH, Heran BS, Perez MI, Wright JM. Blood pressure lowering efficacy of beta-blockers as secondline therapy for primary hypertension. Cochrane Database of Systematic Reviews. 2010;1:CD007185.

26. Lindholm LH, Carlberg B, Samuelsson O. Should $\beta$ blockers remain first choice in the treatment of primary hypertension? A meta-analysis. Lancet. 2005;366:1545-53.

27. Wiysonge CS, Bradley HA, Volmink J, Mayosi BM, Mbewu A, Opie LH. Beta-blockers for hypertension. Cochrane Database of Systematic Reviews. 2012;11:CD002003.

28. Margolis KL, O'Connor PJ, Morgan TM, Buse JB, Cohen RM, Cushman WC, et al. Outcomes of combined cardiovascular risk factor management strategies in type 2 diabetes: the ACCORD randomized trial. Diabetes Care. 2014;37:1721-8.

29. Jawa A, Nachimuthu S, Pendergrass M, Asnani S, Fonseca V. Beta-blockers have a beneficial effect upon endothelial function and microalbuminuria in African-American subjects with diabetes and hypertension. J Diabetes Complications. 2008;22:303-8.

30. Torp-Pedersen C, Metra M, Charlesworth A, Spark P, Lukas MA, Poole-Wilson PA, et al. Effects of metoprolol and carvedilol on pre-existing and new onset diabetes in patients with chronic heart failure: data from the Carvedilol Or Metoprolol European Trial (COMET). Heart. 2007;93:968-73.

Cite this article as: Hiremath SB, Lokikere SD. Carvedilol versus beta- 1 blockers as antihypertensive drugs in type-2 diabetes mellitus and pre-diabetic patients with features of metabolic syndrome: a meta-analysis. Int J Basic Clin Pharmacol 2016;5:1380-8. 